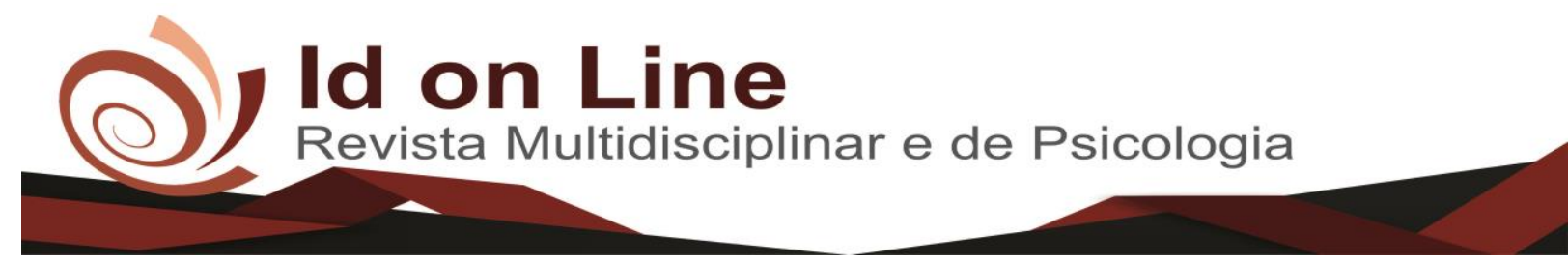

Comment

\title{
Leitura e Escrita: Um Relato de Dificuldades de Aprendizagem nos anos iniciais do Ensino Fundamental
}

\author{
Adriana Maria dos Santos $^{1}$; Aurenia Pereira de França ${ }^{2}$; Maria do Socorro Cecilio Sobral ${ }^{3}$
}

\begin{abstract}
Resumo: O presente artigo teve como objetivo relatar as dificuldades de aprendizagem na leitura e escrita nos anos iniciais e nortear para onde e como deve-se agir para obter resultados satisfatórios na aprendizagem. A justificativa por essa temática consiste no fato de ser extremamente importante saber ler e escrever nem que seja o mínimo possível para viver bem diante da sociedade e que as dificuldades de leitura e escrita não são superadas no processo e são levadas durante toda a vida escolar comprometendo o desempenho do aluno. Através dele foi possível mostrar em consulta A visão de Gadotti quanto ao ensino e quanto ao papel do professor nesse ciclo de aprendizagem e citar Freire como uma das inspirações, diante da desenvoltura que aponta o papel e a importância do professor e do aluno no processo de ensino e aprendizagem que vai além de apenas ensinar. A pesquisa aqui presente teve cunho qualitativo exploratório e foi tipo bibliográfico através de pesquisa e estudo em livros, artigos retirados da internet entre outros. Foi ainda possível afirmar que diante do presente trabalho obteve-se a ideia de que o aluno é um ser que está aprendendo com o mundo e é preciso observá-lo e descrevê-lo para que se possa haver uma adaptação curricular no processo de ensino que esteja totalmente voltado para a melhoria da aprendizagem do aluno. Concluiu-se então que é necessário desenvolver ações pedagógicas e de cunho adaptativo para aprendizagem desses alunos, para que ocorra diante do processo ensino aprendizagem a soma de resultados na alfabetização de alunos com dificuldades na leitura e escrita. Tais resultados só serão possíveis com empenho e dedicação total do professor, estando presente e mostrando o mundo como meio de aprendizagem e dando autonomia para o aluno aprender fazendo.
\end{abstract}

Palavras-Chave: Leitura e escrita, dificuldades de aprendizagem, ensino fundamental.

\section{Reading and Writing: A Report of Learning Difficulties in the Initial Years of Elementary Education}

\begin{abstract}
The aim of this article was to report learning difficulties in reading and writing in the initial years and to orient where and how to act to obtain satisfactory results in learning. The justification for this theme is the fact that it is extremely important to be able to read and write even if it is the least possible to live well in front of society and that the difficulties of reading and writing are not overcome in the process and are carried throughout the school life, the student's performance. Through him it was possible to show in consultation Gadotti's view on teaching and on the role of the teacher in this cycle of learning and to quote Freire as one of the inspirations, given the resourcefulness that points out the role and importance of the teacher and the student in the process of teaching and learning that goes beyond just teaching. The present research had an exploratory qualitative aspect and was bibliographic type through research and study in books, articles taken from the internet among others. It was also possible to affirm that before the present work the idea was obtained that the student is a being who is learning with the world and it is necessary to observe and to describe it so that there can be a curricular adaptation in the
\end{abstract}

\footnotetext{
${ }^{1}$ Faculdade de Ciências Humanas do Sertão Central (FACHUSC). E-mail: adrianamariadossantos95@gmail.com;

${ }^{2}$ Mestrado em Ciência da Linguagem na UNICAP, Especialista em Metodologia do Ensino e Especialista em Ciência da Educação Supervisão Pedagógica. Graduação em Letras - Francês pela Universidade Regional do Cariri, Brasil. Professora na Faculdade de Ciências Humanas do Sertão Central (FACHUSC). E-mail: aureniafranca@gmail.com

${ }^{3}$ Mestrado em Educação em Ciências pela Fundação de Apoio à Universidade Federal do Rio Grande do Sul, Brasil. Professora da Faculdade de Ciências Humanas do Sertão Central (FACHUSC). E-mail: socorrosobral@bol.com.br
} 
teaching process that is fully focused on improving student learning. It was concluded that it is necessary to develop pedagogical and adaptive actions for the learning of these students, so that before the process teaching learning the sum of results in the literacy of students with difficulties in reading and writing. These results will only be possible with dedication and total dedication of the teacher, being present and showing the world as a means of learning and giving autonomy for the student to learn by doing.

Keywords: Reading and writing, learning difficulties, elementary school.

\section{Introdução}

Diante das dificuldades de aprendizagem e das necessidades específicas de cada discente, podemos afirmar que aprender a ler e escrever pode ser no mínimo dificultoso e chegar a um patamar de trazer problemas não só de aprendizado, mas também sociais.

Aprender a ler a cada dia se torna verdadeiramente mais necessário para todas as pessoas. Mas não basta só saber ler. É preciso ser letrado. Nos dias atuais a alfabetização se faz a partir do alfabetizar letrando, onde afasta o aluno de ser apenas uma pessoa que escreve, mas que não reconhece algo que o mesmo escreveu ou que tenha vindo de outro.

O estudo desenvolvido tem como por objetivo relatar as dificuldades de aprendizagem na leitura e escrita nos anos iniciais e nortear para onde e como deve-se agir para obter resultados satisfatórios na aprendizagem. Com indicação de dinâmicas que auxiliem no ensino de crianças com dificuldade na leitura, no mesmo está apresentado que é relevante e necessário que o aluno tenha autonomia para ser quem quer ser e aprender no seu tempo de aprendizagem. Através dessa pesquisa foi possível concluir que no ensino para alunos não só com dificuldade na aprendizagem, mas também qualquer outro que é preciso haver adaptação no currículo e no ensino, pois além de cada aluno aprender no seu tempo cada um deles aprende de uma forma diferente. Diante disso é possível afirmar que o professor deve estar apto e interessado no desenvolvimento e na aprendizagem do aluno, onde ele pode e deve agir de maneira prática e lógica desenvolvendo ações e estratégias pedagógicas de ensino que auxiliem o rofessor no ato de ensinar e o aluno na arendizagem.

Entre as ações pedagógicas que podemos citar está a de ensinar a criança apresentando o mundo para a mesma. E como seria tal desenvoltura? Ela se daria através de mostrar objetos ao redor do aluno e seus respectivos nomes reproduzidos. Fazendo assim que sempre que o 
aluno veja e observe tal objeto possa assemelhar a palavra e sempre que ler a palavra assemelhe ao objeto.

O desenvolvimento deste trabalho se justifica pelo fato da percepção nas dificuldades de aprendizagem dos alunos, as motivações que resultam nas dificuldades e como tentar abdicar dos meios de ensino regular e apossar-se de ações que auxiliem o aluno a ultrapassar toda e e qualquer barreira que venha impossibilitar o seu aprendizado.

O mesmo vem com sentido de dar norteamento e auxílio diante das necessidades encontradas no ensino. Cada dia vê-se o meio social de forma insegura e catastrófica e um dos papeis do professor em sala de aula está voltado para trazer segurança e alívio social para o aluno no meio escolar, fazendo que ele possa levar seu aprendizado para toda sua vida, pois a e qualquer barreira que venha impossibilitar o seu aprendizado.

\title{
Referencial teórico
}

\section{Leitura e escrita}

Desde o início da educação escolar, uma das maiores preocupações, se não a maior, é a aprendizagem na leitura e na escrita. Tais ações desenvolvidas no decorrer da vida acadêmica trazem resultados que se levarão por toda a vida particular do aluno.

Lajolo fala que:

\begin{abstract}
"O leitor que, diante de um texto escrito, tenha a autonomia suficiente para atuar desde a decodificação da mensagem no seu aspecto literal até o estabelecimento de um conjunto mínimo de relações estruturais, contextuais que ampliem a significação do texto a tal ponto que se possa considerar ter havido, efetivamente, apropriação da mensagem, do significado na multiplicidade de relações estabelecidas entre texto e leitor, entre textos, com o mundo" (LAJOLO, 1999, p. 105).
\end{abstract}

Tal afirmação diz que a leitura traz o total conhecimento daquilo que se lê e se compreende, fazendo da leitura um símbolo de compreensão e de aprendizagem quanto ao que se passa diante do mundo. O bom leitor tem o poder de ver e recriar o mundo através da sua visão, sendo um bom visionário daquilo tudo que aprende, com condição total de conseguir construir novos conhecimentos através daquilo que se aprendeu.

Podemos então ver a escrita como representação daquilo que queremos reproduzir ou 
produzir, diante daquilo que conhecemos ou queremos conhecer. Ambas (leitura e escrita) andam juntas no processo de ensino e de aprendizagem, as mesmas ensinadas e aprendidas com eficiência podem alcançar o desenvolvimento do aluno diante de tudo aquilo que ele precisa aprender como acadêmico escolar.

\section{Alfabetização: as dificuldades de aprendizagem no início da vida escolar}

Ao passar pela alfabetização é comum para qualquer criança que encontre dificuldades em sua aprendizagem, desde que aprender requer atenção e desejo pelo aprendizado, como pensa Gadotti quando diz que para aprender é necessário gostar de aprender, ter prazer em ensinar, como um jardineiro que cuida com emoção do seu jardim, de sua roça e amar aquele que aprende (GADOTTI, 2003). Essas dificuldades sempre aparecem por existirem necessidades específicas em cada aluno, sendo que as mesmas devem ser atendidas e observadas tais necessidades podem ser tanto físicas quanto psicológicas ou até mesmo um transtorno ou um distúrbio adquirido ou genético.

As dificuldades na aprendizagem podem acontecer ao tentar reconhecer uma letra, um número e até mesmo uma imagem, e partir para o reconhecimento de palavras frases e até textos. Identificar a dificuldade é o primeiro passo para desenvolver ações que a resolvam. Sendo assim o professor deve estar atento a cada passo do aluno, observando cada sinal de desenvolvimento, de dificuldade e de facilidade em aprender aquilo que lhe é ensinado.

Para iniciar ações de leitura e escrita é preciso conhecer o discente, para isso é necessário observa-lo e descrevê-lo para si através da visão docente. Diante desse reconhecimento o professor deve articular ações de adaptação curricular para cada aluno acerca de seu ritmo de aprendizagem. Para Gadotti (2003 e p) o professor precisa entender o aluno, e entender o fato de que ele precisa aprender sobre o mundo de maneira cautelosa e no seu próprio tempo.

Nesse aspecto o docente está considerando as diferenças que cada ser apresenta conforme sua bagagem genética e precisará ir muito além buscando compreender a relação do aluno com o conhecimento construído pela humanidade como ressalta o teórico a seguir:

O professor precisa saber, contudo, que é difícil para o aluno perceber essa relação entre o que ele está aprendendo e o legado da humanidade. O aluno que não perceber essa relação não verá sentido naquilo que está aprendendo e não aprenderá, resistirá à 
aprendizagem, será indiferente ao que o professor estiver ensinando. Ele só aprende quando quer aprender e só quer aprender quando vê na aprendizagem algum sentido. Ele não aprende porque é burrinho. Ao contrário, às vezes, a maior prova de inteligência encontra-se na recusa em aprender. (GADOTTI,2003 P.47)

A alfabetização pode ser uma experiência dificultosa e aterrorizante para o aluno, se não houver dedicação e assiduidade do professor no ensino essa experiência com resultados desastrosos pode se desencadear por toda a vida do discente.

\section{Dificuldade na leitura e escrita, algo que pode ser superado}

Conseguir ler e escrever bem requer treino e um bom empenho e dedicação da parte do aluno e do professor. Essa dedicação deve estar voltada inteiramente para a tentativa assídua e corriqueira de ambas as partes para que se tenha os objetivos alcançados. Tanto o ensino quanto a aprendizagem devem estar voltados ligeiramente para as dificuldades do aluno, porém sempre se apegando a aprendizagem de coisas novas para que possa ter um auxílio de novos conteúdos e práticas de desenvoltura.

Para abdicar da dificuldade e alavancar a aprendizagem do aluno, o professor deve incita-lo a conhecer o mundo. Como afirma Paulo Freire (1992) quando diz que a leitura do mundo precede a leitura da palavra, daí que a posterior leitura desta não possa prescindir da continuidade daquele. Linguagem e realidade se prendem dinamicamente. Diante disso podemos afirmar que para iniciar o ensino da leitura deve-se primeiro apresentar o mundo ao aluno, pois além de equiparar a linguagem a vida, ao fazê-lo é possível ver e levar em conta o conhecimento já existente do aluno.

De acordo com Silva (1988 p.64) é preciso ler para compreender os textos, participando criticamente da dinâmica do mundo da escrita e posicionando-se frente à realidade esta a finalidade básica que estabelecemos para as práticas de leitura na escola. Assim o aluno deve conhecer e estar apto ao mundo leitor e a leitura deve estar voltada para sua realidade

Mas como usar o que está em volta na aprendizagem? Ao usar a imagem de uma cadeira para depois mostrar a palavra cadeira fará com que o aluno passe a dar significado a palavra. Sendo assim ele verá que como o exemplo acima dado, tudo ao nosso redor tem nome e significado.

Quanto a prática da escrita, que se volta para representação da grafia, traz ao aluno a 
oportunidade de representar o seu conhecimento e aprendizagem. O que lhe auxilia na leitura pois através da escrita o discente pode representar a palavra que está lendo ou conhecendo. Para isso é necessário que anteriormente o aluno tenha aprendido o alfabeto e os números, que são signos que delimitam o início do conhecimento e da aprendizagem acadêmica. Bottrel (1998, p.35) diz que no aprendizado da escrita a criança descobre o alcance da redação e do desenho e dispõe de cada um deles conforme seu objetivo de comunicação. Nesse sentido o discente pode ver na escrita a oportunidade de se comunicar e desenvolver o que pensa através daquilo que ele representa escrevendo ou até mesmo desenhando.

Sendo assim, além de tentar trazer aos alunos os hábitos de leitura, é preciso estar constantemente incitando ele a ler e escrever. As repetições de ações podem ser delimitadoras na aprendizagem quando funcionarem bem, e quando falharem ou até mesmo fracassarem sempre servirão de auxílio para a melhoria da prática de ensino.

Superar problemas na aprendizagem podem ser difíceis, mas desde que seja feito com atenção e cuidado é possível que se encontre resultados reais e longíquos onde o discente poderá carregar durante toda sua vida acadêmica e pessoal.

\section{Resultados de ações norteadoras de resultados para a aprendizagem}

Somente delimitando ações que estejam voltadas para dificuldade de cada aluno é que se pode obter um resultado seguro e incólume, sendo assim, tais resultados serão duradouros e levados para toda a vida. Tais ações devem estar presentes diariamente na vida escolar, para que seja efetuado com eficácia o que é ensinado e aprendido.

Entre essas ações está o amor pelo ensino e por quem aprende. Gadotti (2003, p.21) relata que muitas professoras, quando perguntadas porque escolheram essa profissão respondem: porque gosto de criança. É uma resposta correta e significativa, mas ela não é levada em conta no seu processo de formação. Sendo assim, diante dessa afirmativa podemos perceber que gostar do alunado é necessário, mas não é tudo. O amor pela a profissão é essencial, quando se faz aquilo que se gosta, é mais provável que o professor consiga se sair melhor nas suas práticas e nos seus resultados alcançados durante a sua desenvoltura de ensino.

É previsto que os alunos precisam aprender a ler, compreender e interpretar palavras, textos e até mesmo imagens, esses são conhecimentos acadêmicos norteadores de resultados 
legais e duradouros já que aprender a ler e escrever precede a aprendizagem de outros conteúdos. Formando-se assim uma pessoa letrada e não simplesmente alfabetizada, acontecendo cada coisa no seu devido tempo de realização. A pesquisadora afirma que:

\footnotetext{
A leitura é o processo mediante o qual se compreende a linguagem escrita. Nesta compreensão intervêm tanto o texto, sua forma e conteúdo, como o leitor, suas expectativas e conhecimentos prévios. Para ler necessitamos, simultaneamente, manejar com destreza as habilidades de decodificação e aportar ao texto nossos objetivos, ideias e experiências prévias (SOLÉ, 1998, p.23).
}

Entre tais ações está a de dar autonomia para o aluno desenvolver naturalmente, de forma contínua e sem nenhum tipo de ação mecânica, onde no lugar de produzir ele apenas reproduzirá. Sendo assim o aluno terá a liberdade de criar e construir o seu conhecimento diante das suas aprendizagens diárias, ele precisa de liberdade e estímulo para aprender da sua forma e no seu tempo. Solé (1998 p.76), diz que o bom ensino não é apenas o que se situa um pouco acima do nível do aluno, mas o que garante a interiorização do que foi ensinado e seu uso autônomo por parte daquela. Logo é possível afirmar que o papel do professor no processo ensino aprendizagem da leitura e da escrita deve estar voltado para ensinar ao aluno e lhe dar auxílio, porém, conforme se apresente resultados, o docente deve se distanciar desse ensino, fazendo com que o mesmo não seja totalitário, e passe a observar e auxiliar somente quando for realmente necessário.

Permitir que o aluno crie sua própria interpretação de mundo, fazendo com que ele construa sua própria história é de extrema relevância para o contexto educacional. Logo vemos que entre as ações de auxílio ao desenvolvimento do aluno está em dar autonomia ao mesmo, auxiliá-lo em sua aprendizagem, ter amor pelo ensino e permitir que ele conheça ao mundo a aprendendo com o mesmo.

\section{Metodologia}

$\mathrm{O}$ presente estudo tem cunho qualitativo de tipo bibliográfico. $\mathrm{O}$ mesmo foi desenvolvido através dos teóricos Gadotti, Lajolo, PauloFreire, Silva, Bottrel, Isabel solé e Abreu e também com ajuda de pesquisa em livros e artigos retirados da internet dos quais trouxe um norteamento para o segmento da pesquisa. 


\section{Resultados e Discussão}

Foi observado e avaliado que para haver um bom ensino e resultado diante das práticas pedagógicas deve-se ter apreço pelo ensino e pela aprendizagem. Ensinar deve ser prazeroso assim como aprender. $\mathrm{O}$ que quer dizer que é verdadeiramente preciso incentivar o aluno a ter gosto pela aprendizagem para que se tenha dedicação de ambas as partes através de dinâmincas que interesse o aluno como atividades lúdicas, uso de tecnologias da informação em sala de aula é muito oportuno considerando que: A maioria das pessoas tem como leitura habitual apenas a mídia. É lá que vão buscar os seus tijolos para construir, mas pouca coisa tem serventia. (...) Na verdade, a mídia nos oferece uma espécie de visão tubular das coisas. É como se olhássemos apenas a parte da realidade que ela nos permite olhar e da maneira como ela quer que nós a interpretemos. (ABREU, 2000, P.35)

Igualmente foi perceptível que a adaptação curricular e no ensino traz resultados que são decisivos e importantes na aprendizagem, pois os mesmos levam em conta as dificuldades dos alunos à risca, fazendo valer a necessidade por resultados através da dedicação pessoal.

Ver também que o mundo é objeto de ensino e também de aprendizagem foi um resultado inesperado, não que não houvesse imaginação quanto a hipótese e sim por perceber que o mundo e o que existe nele também ensina, e que tirar proveito disso é inteligente e requer habilidade.

Acima de tudo foi possível perceber que dar autonomia ao aluno para aprender e ser quem ele é no meio escolar e de aprendizado pode trazer resultados eficazes, fazendo com que o aluno aprenda a fazer fazendo. Ver que a leitura deve ser incentivada mostra que deve-se formar leitores desde sempre para que os mesmos venham a se tornar escritores e criadores de suas próprias histórias.

\section{Considerações Finais}

Nos dias atuais tornou-se extremamente importante saber ler e escrever nem que seja o mínimo possível para viver bem diante da sociedade. Quando é dito viver bem, relata-se diante dos meios de comunicação e de compra por exemplo. E não se fala somente de comunicação digital, mas também da comunicação direta e interpessoal, que mesmo estando hoje abalada 
diante da facilidade da comunicação virtual, ainda é presente na vida das pessoas.

Logo podemos ver que aquele que não lê ou não compreende aquilo que lê torna-se facilmente manipulado. Sendo levado sempre por aquilo que se houve. A partir daí que vê-se a importância da leitura e da compreensão de textos.

Sendo assim o papel da leitura e escrita se torna de extrema importância e de grande valor pois atua no desenvolvimento acadêmico e pessoal do alunado. Para que haja esse aprendizado de forma segura e real o professor deve estar apto para trabalhar com afinco na busca de resultados mediante as dificuldades de cada aluno. Produzindo estratégias de ensino e aplicando-as na sua prática diária.

A missão do professor não se resume apenas em ensinar a ler e escrever, mas também princípios morais. Tais como o carinho e afeto por quem lhe ensina que deve partir primeiramente do docente. O professor deve ser profissional e buscar posturas que sejam eficazes no ensino e na aprendizagem, tais posturas parte de uma adaptação no currículo voltada tão somente para a necessidade específica do aluno, pois a mesma também está voltada para um problema transtorno ou distúrbio que pode ou não ser corrigido, avaliado e tratado, mas que pode ter resultados positivos quanto a diminuição das dificuldades e também em aspectos de comportamento.

Um dos aspectos importantíssimos no ensino da leitura e escrita para se obter resultados importantes e reais é o incentivo ao hábito de ler. Desde a leitura de palavras até a que se dá início na aprendizagem que é a leitura de imagens. Pedir e incentivar que os alunos aprendam letras, números e imagens que são signos extremamente presentes na sua aprendizagem, pode ser o início de um a vida saudavelmente leitora, com desejo pelo aprendizado e pelo conhecimento.

É preciso não só amar a profissão de professor, mas também fazer com que o aluno tenha o mesmo sentimento pela aprendizagem. Sendo assim o mesmo sentirá prazer em suas descobertas.

\section{Referências}

BOTTREL, I. A. Crianças no caminho do Jornalismo. Revista AMAE Educando. Belo Horizonte, 1998. 
FREIRE, Paulo. A importância do ato de ler: em três artigos que se completam. São Paulo: Cortez, 1992.

. Pedagogia da autonomia: saberes necessários a prática educativa. São Paulo: Editora paz e terra, 1996.

GADOTTI, Moacir. Boniteza de um sonho: ensinar-e-aprender com sentido. Moacir Gadotti. - Novo Hamburgo: Feevale, 2003.

LAJOLO, Marisa. A importância do ato de ler. São Paulo: Moderna, 2003.

SILVA, Ezequiel T. da. A leitura no contexto escolar. Série Idéias n.5. São Paulo: FDE, 1988.

SOLÉ, Isabel. Estratégias de Leitura. Porto Alegre: Artmed, 1998.

Como citar este artigo (Formato ABNT):

SANTOS, Adriana Maria dos; FRANÇA, Aurenia Pereira de; SOBRAL, Maria do Socorro Cecilio. Leitura e Escrita: Um Relato de Dificuldades de Aprendizagem nos anos iniciais do Ensino Fundamental. Id on Line Rev.Mult. Psic., 2018, vol.12, n.42, Supl. 1, p. 481-490. ISSN: 1981-1179.

Recebido: 08/11/2018;

Aceito: $12 / 11 / 2018$ 